\title{
Adaptive method of lines for multi-component aerosol condensational growth and $\mathrm{CCN}$ activation
}

\author{
S. Arabas and H. Pawlowska \\ Institute of Geophysics, Faculty of Physics, University of Warsaw, Pasteura 7, 02-093 Warsaw, Poland \\ Received: 29 July 2010 - Published in Geosci. Model Dev. Discuss.: 19 August 2010 \\ Revised: 17 December 2010 - Accepted: 3 January 2011 - Published: 21 January 2011
}

\begin{abstract}
The process of formation of cloud droplets on an ensemble of aerosol particles is modelled by numerous investigators using the method of lines (MOL). The method involves discretisation of the aerosol size spectrum into bins whose positions evolve with time. One of the drawbacks of the method is its poor representation of the aerosol spectrum shape in the region between the unactivated aerosol mode and the activated droplet mode. An adaptive grid refinement procedure is introduced. The procedure splits any overly wide bins into several narrower ones during integration. The number of new bins added is a function of particle concentration in the bin being split. Application of the grid refinement procedure results in suppression of the sensitivity of the computed cloud droplet spectrum characteristics such as droplet number concentration or effective radius to the initial grid choice. A model of droplet formation on multicomponent aerosol is formulated for the purpose of the study. Model formulation includes explicit treatment of the droplet temperature evolution. Several examples of the model setup are used to demonstrate model capabilities. Model results are compared to those without adaptivity. A C++ implementation of the model is available as an electronic supplement of the paper.
\end{abstract}

\section{Introduction}

Cloud droplets form on cloud condensation nuclei, CCN (Aitken, 1880, and the works of his contemporaries). $\mathrm{CCN}$ are the atmospheric aerosol that contribute to the heterogeneous nucleation of the water vapour. As a result,

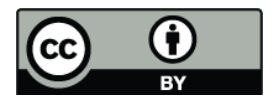

Correspondence to: S. Arabas (sarabas@igf.fuw.edu.pl) the microphysical properties of clouds (i.e. the size spectrum of droplets) strongly depend on physicochemical properties of aerosol particles (see e.g., the review of McFiggans et al., 2006).

Owing to the fact that the radiative properties of clouds and their ability to precipitate are both dependant on characteristics of the size spectrum of droplets (see e.g., the review of Stevens and Feingold, 2009), the description of the activation process is of importance to the studies on aerosolcloud-climate interactions (e.g., Kulmala et al., 2009a,b).

Aerosol growth by condensation of water vapour is conceptualised as a twofold diffusion process. First, there is the diffusion of water molecules towards the particle, and the condensation of water vapour on the particle surface. Concurrently, the latent-heat release triggers the diffusion of heat from the particle, hence the system is akin to the wet-bulb thermometer described by Maxwell (1878). The chemical composition of the growing particle and its curvature determine the vapour pressure over its surface (Köhler, 1936, and his earlier works), and hence influence the pace of the diffusion process. Additional complexities are introduced when considering an ensemble of particles of different sizes (Howell, 1949; Kraus and Smith, 1949), with different shapes and soluble material content (Kornfeld, 1970), nuclei of different solubility (Fitzgerald, 1974), and finally nuclei composed of different chemical species (Lee and Pruppacher, 1977) all competing simultaneously for the available water vapour. Yet another level of detail is reached when considering the feedback with the dynamics of the air (turbulence, entrainment and mixing), the interactions between the individual droplets (i.e. collision/coalescence) or more sophisticated description of cloud chemistry, all being however distant from the scope of this study. Numerical solutions of the problem had been repeatedly challenged using the fastest computers in the early years of electronic

Published by Copernicus Publications on behalf of the European Geosciences Union. 
computing, starting with the studies of Mordy (1959) performed using the Swedish BESK computer, and the study of Neiburger and Chien (1960) carried out on the American SWAC.

The key complexity of the problem, from the mathematical standpoint, is the necessity to solve the partial differential equation describing the evolution of aerosol size spectrum. Analytical solutions to the problem (or semianalytical estimates) can be derived only under significant approximations (see e.g., Squires, 1952; Twomey, 1959; Johnson, 1981; Gelbard, 1990; Khvorostyanov and Curry, 2009, and references therein). Numerical solutions based on finite-difference approach using a fixed-grid representation of the size spectrum may be used (also called Eulerian or fixed-bin approaches). Such methods are characterised by computational difficulties, and the complexity of the description of chemical properties of aerosol (see e.g., Chap. 5 in Williams and Loyalka, 1991).

The partial differential equation may be reduced to a system of ordinary differential equations (ODE) by spatial discretisation of the initial size spectrum into sections with constant-in-time number of particles. The boundaries of these sections are then allowed to evolve with time, hence the name moving-sectional technique/Lagrangian approach/full-moving structure (Jacobson, 1999, Sect. 14.5 therein) or method of characteristics (Gelbard, 1990), or method of lines (Debry et al., 2007). This approach was introduced by Howell (1949), and has since been used in modelling CCN activation (e.g., Mordy, 1959; Neiburger and Chien, 1960; Fitzgerald, 1974; Hänel, 1987; Feingold and Heymsfield, 1992; Nenes et al., 2001b; Grabowski et al., 2010). Such formulation of the model eliminates the computational difficulties inherent to numerical treatment of partial differential equations, and allows accurate description of the evolution of aerosol composition because particle properties such as mass of solute are retained throughout the computation.

The moving-sectional technique does pose computational difficulties because of the ODE system stiffness (see e.g., the discussion by Gelbard, 1990). The physical process of competition for the water vapour between particles of different sizes and chemical composition can be correctly resolved in a numerical solution only under sufficiently short time-steps. The approximations inherent to the bin-representation of the aerosol size spectrum introduce significant uncertainties to the solution if low-resolution discretisation is used (Korhonen et al., 2005). The issues of stiffness of the system and of appropriate timestep choice are addressed herein by using an adaptive Gear-type ODE solver. The issue of sensitivity of the results to the bin-number choice, being one of the factors causing discrepancies among results of different models (Kreidenweis et al., 2003) is the very focus of this study. The problem is tackled by introducing an adaptive size-spectrum discretisation refinement. The resultant solution procedure is analogous to what is referred to as the adaptive method of lines (e.g. Wouwer et al., 2001).

The following section of the paper covers model formulation and implementation. Sample results are discussed in the third section. First, a set of model runs without adaptivity is discussed revealing the sensibility of the results to parameters controlling the discretisation of the initial aerosol size spectrum (Sects. 3.1 and 3.2). Second, the properties and efficacy of the adaptive size-spectrum discretisation method are presented (Sect. 3.3). The fourth section concludes the paper with a brief outlook on the possible applications of the discussed method within different domains of atmospheric research.

\section{Model formulation and implementation}

The model provides a description of the droplet formation process at the initial stage of cloud-formation triggered by vertical air motion (i.e. in convective or orographic clouds). The model utilises the method of lines (MOL) for numerically solving the so-called dynamic equation of aerosol growth by condensation. A list of symbols used in the text is given in Appendix A.

\subsection{Air-parcel system and its governing equations}

The model describes an air parcel with the temperature $T$, pressure $p$, and specific humidity $q_{\mathrm{v}}$ being vertically displaced with constant velocity $w$. The parcel does not exchange heat or mass with the environment and hence its heat budget (neglecting terms related to mass and heat content of the particles) is expressed as:

$c_{p}\left(q_{\mathrm{v}}\right) d T=\frac{R\left(q_{\mathrm{v}}\right) T}{p} d p-l_{\mathrm{v}}(T) d q_{\mathrm{v}}$

where $l_{\mathrm{v}}$ is the latent heat of evaporation, $c_{p}\left(q_{\mathrm{v}}\right)=c_{p \mathrm{v}} q_{\mathrm{v}}+$ $c_{p \mathrm{~d}}\left(1-q_{\mathrm{v}}\right)$ is the specific heat capacity at constant pressure of moist air, and $R\left(q_{\mathrm{v}}\right)=R_{\mathrm{v}} q_{\mathrm{v}}+R_{\mathrm{d}}\left(1-q_{\mathrm{v}}\right)$ is the gas constant of moist air. $R_{\mathrm{V}}$ and $R_{\mathrm{d}}$ depict gas constants for water vapour and dry air, respectively; $c_{p \mathrm{v}}$ and $c_{p \mathrm{~d}}$ depict specific heat capacities at constant pressure for water vapour and dry air, respectively.

The parcel's pressure adapts instantaneously to the environmental value defined through the hydrostatic equilibrium. It follows that the pressure changes are driven by the vertical velocity of the parcel:

$\frac{d p}{d t}=-\frac{p g}{R\left(q_{\mathrm{v}}\right) T} w$

where $g$ is the gravitational acceleration.

Physical characteristics of the aerosol suspended in the parcel are described by a set of probability density functions (PDFs) defining the size spectra of dry aerosol, each PDF corresponding to different chemical composition. The dry 
spectra $n_{\mathrm{d}}^{[c]}\left(r_{\mathrm{d}}\right)$ are invariant with time, and are defined as a function of dry radius $r_{\mathrm{d}}$, separately for each chemical component $c$. Each dry spectrum has a corresponding wet spectrum $n_{\mathrm{W}}^{[c]}\left(r_{\mathrm{w}}, t\right)$ defined analogously but varying with time. Both $n_{\mathrm{d}}^{[c]}$ and $n_{\mathrm{w}}^{[c]}$ are expressed in terms of particle number per unit mass of moist air, and are referred to as specific concentrations. The total mass of particles is assumed to be proportional to the third moment of the wet PDFs (i.e. neglecting the contribution from soluble substance):

$\left\langle r_{\mathrm{w}}^{3}\right\rangle=\sum_{c} \frac{1}{N^{[c]}} \int_{0}^{\infty} n_{\mathrm{w}}^{[c]}\left(r_{\mathrm{w}}, t\right) r_{\mathrm{w}}^{3} d r_{\mathrm{w}}$

where $N^{[c]}=\int_{0}^{\infty} n_{\mathrm{W}}^{[c]} d r_{\mathrm{w}}$ is the total specific concentration for a given chemical component. For each wet spectrum a corresponding particle temperature field $T_{\mathrm{w}}^{[c]}\left(r_{\mathrm{w}}, t\right)$ is also introduced.

Water is considered to be present in liquid and vapour phases only. The diffusion of both water vapour and heat around the particles is treated assuming stationary state with time-varying boundary conditions what results in the following form of the Fick's first law and Fourier's law (cf. e.g., Chap. 7 in Rogers and Yau, 1989):

$$
\begin{aligned}
& \frac{d M}{d t} \frac{1}{4 \pi r_{\mathrm{w}}^{2}}=\frac{D}{r_{\mathrm{w}}}\left(\rho_{\mathrm{v}}-\left.\rho_{\mathrm{v}}\right|_{\text {particle surface }}\right) \\
& \frac{d Q}{d t} \frac{1}{4 \pi r_{\mathrm{w}}^{2}}=\frac{K}{r_{\mathrm{w}}}\left(T-T_{\mathrm{w}}\right)
\end{aligned}
$$

where $M=4 \pi r_{\mathrm{w}}^{3} \rho_{\mathrm{l}} / 3$ is the mass of a particle of density $\rho_{\mathrm{l}}$, $\rho_{\mathrm{v}}$ is the density of water vapour in the parcel, $D$ and $K$ are diffusion coefficients discussed below. The liquid water density $\rho_{1}$ is assumed constant. The two diffusion equations are coupled via a heat budget equation:

$d Q=M c_{1} d T_{\mathrm{w}}-l_{\mathrm{v}}\left(T_{\mathrm{w}}\right) d M$

where $c_{1}$ is the specific heat capacity of liquid water.

Equations (4) and (5) evaluated with diffusion coefficients $D$ and $K$ independent of particle size represent the socalled continuum régime in which the efficiency of diffusion is limited solely by the diffusivity of water vapour in air. Continuum régime is applicable for particles of sizes larger than the free path of water molecules in air (i.e. $r_{\mathrm{w}} \gg$ $0.1 \mu \mathrm{m})$. Evolution of size of much smaller particles is described using the molecular régime, and the transition between the two régimes may be approximately allowed for by introducing a particle radius-dependency to the diffusion coefficient (Langmuir, 1944, discussion of Eq. 52 therein). Here, we apply the transition régime correction factors of Fuchs and Sutugin (1970) in the form suggested for cloud modelling by Laaksonen et al. (2005):

$$
D=D_{0} \frac{1+\frac{\lambda_{D}}{r_{\mathrm{w}}}}{1+1.71 \cdot \frac{\lambda_{D}}{r_{\mathrm{w}}}+1.33 \cdot\left(\frac{\lambda_{D}}{r_{\mathrm{w}}}\right)^{2}}
$$

$$
K=K_{0} \frac{1+\frac{\lambda_{K}}{r_{\mathrm{w}}}}{1+1.71 \cdot \frac{\lambda_{K}}{r_{\mathrm{w}}}+1.33 \cdot\left(\frac{\lambda_{K}}{r_{\mathrm{w}}}\right)^{2}}
$$

where $D_{0}$ is the diffusivity of water vapour in air (assumed constant), $K_{0}$ is the thermal conductivity of air (assumed constant), $\lambda_{D}$ is the mean free path of water vapour in air, and $\lambda_{K}$ is a length scale for heat transfer in air (the ratio of a mean free path to a characteristic length is called the Knudsen number). The two last are defined as:

$\lambda_{D}=2 D_{0}\left(2 R_{\mathrm{v}} T_{\mathrm{w}}\right)^{-1 / 2}$

$\lambda_{K}=\frac{4}{5} K_{0} \frac{T}{p}\left(2 R_{\mathrm{d}} T\right)^{-1 / 2}$

(Williams and Loyalka, 1991, Eqs. 6.6 and 6.33 therein).

The condensation/evaporation of water on/from the aerosol is the only source of changes in specific humidity $q_{\mathrm{v}}$ and thus:

$\frac{d q_{\mathrm{v}}}{d t}=-\left(1-q_{\mathrm{v}}\right) \frac{4 \pi \rho_{1}}{3} \frac{d}{d t}\left[\left\langle r_{\mathrm{w}}^{3}\right\rangle \sum_{c} N^{[c]}\right]$

where the $\left(1-q_{\mathrm{v}}\right)$ term stems from the employment of specific quantities.

The density of water vapour at particle surface $\left.\rho_{\mathrm{v}}\right|_{\text {particle surface }}$ in Eq. (4) is assumed to be equal to the equilibrium (saturation) value taking into account the Gibbs-Kelvin and Raoult effects related to surface curvature and composition, respectively (the so-called Köhler curve):

$p_{\mathrm{vs}}=p_{\mathrm{v} \infty}\left(T_{\mathrm{w}}\right) \cdot a\left(r_{\mathrm{w}}, r_{\mathrm{d}}\right) \cdot \exp \left(\frac{2 \sigma}{R_{\mathrm{v}} T_{\mathrm{w}} \rho_{1} r_{\mathrm{w}}}\right)$

where $p_{\mathrm{v} \infty}$ is the equilibrium vapour pressure over plane surface of pure water, $\sigma$ is the surface tension coefficient, and the water activity $a$ is parameterised in accordance with experimental data using the single-parameter representation of Petters and Kreidenweis (2007, Eq. 6 therein):

$a\left(r_{\mathrm{w}}, r_{\mathrm{d}}\right)=\frac{r_{\mathrm{w}}^{3}-r_{\mathrm{d}}^{3}}{r_{\mathrm{w}}^{3}-r_{\mathrm{d}}^{3} \cdot\left(1-\kappa^{[c]}\right)}$

where $\kappa^{[c]}$ is the single parameter representing chemical composition in spectrum $c$. The dry aerosol is assumed to be entirely soluble. A constant surface-tension coefficient $\sigma=0.072 \mathrm{~J} \mathrm{~m}^{-2}$ is used (value for pure water at $298 \mathrm{~K}$ ) in accordance with the parameterisation of Petters and Kreidenweis (2007).

The specific heat capacities of dry air $c_{p \mathrm{~d}}$, and water vapour $c_{p \mathrm{v}}$ are assumed constant (perfect gas), hence the latent heat of evaporation is given by:

$l_{\mathrm{v}}\left(T^{\prime}\right)=l_{\mathrm{v} 0}+\left(c_{p \mathrm{v}}-c_{1}\right) \cdot\left(T^{\prime}-T_{0}\right)$ 
and the equilibrium pressure over a plane surface of pure water (solution of the Clausius-Clapeyron equation) is given by:

$p_{\mathrm{v} \infty}\left(T^{\prime}\right)=p_{0} \cdot \exp \left[\frac{l_{\mathrm{v} 0}-\left(c_{p \mathrm{v}}-c_{1}\right) \cdot T_{0}}{R_{\mathrm{v}} \cdot\left(\frac{1}{T_{0}}-\frac{1}{T^{\prime}}\right)^{-1}}\right]\left(\frac{T^{\prime}}{T_{0}}\right)^{\frac{c_{p \mathrm{v}}-c_{1}}{R_{\mathrm{v}}}}$

where $T_{0}, p_{0}$ and $l_{\mathrm{v} 0}$ correspond to the triple-point values, and $T^{\prime}$ denotes here the temperature for which the formulæ are evaluated. The specific heat capacity of liquid water $c_{1}$ is assumed constant.

\subsection{MOL's ODE system}

As outlined in the first section, the mathematical formulation of the model constitutes a system of ODEs which approximate the partial differential equation for describing the evolution of aerosol size spectrum. This approach is based on an approximation of the PDFs with piecewise constant functions. Here, each bin (numbered by $b$ ) is defined by a constant-in-time number of particles $N^{[c, b]}$ (per unit mass of air), and variable-in-time left and right boundaries $r_{\mathrm{wl}}^{[c, b]}(t)$ and $r_{\mathrm{wr}}^{[c, b]}(t)$. The third moment of the particle size spectrum is thus approximated using:

$$
\int_{0}^{\infty} n_{\mathrm{w}}^{[c]} r_{\mathrm{w}}^{3} d r_{\mathrm{w}}=\sum_{b} N^{[c, b]} \int_{r_{\mathrm{wl}}^{[c, b]}}^{r_{\mathrm{ww}}^{[c, b]}} \frac{r_{\mathrm{w}}^{3}}{r_{\mathrm{wr}}^{[c, b]}-r_{\mathrm{wl}}^{[c, b]}} d r_{\mathrm{w}}
$$

This allows expressing the time derivative of the total mass of wet aerosol without employing partial differentials using:

$$
\begin{aligned}
& \frac{d}{d t}\left[\left\langle r_{\mathrm{w}}^{3}\right\rangle \sum_{c} N^{[c]}\right]=\frac{1}{4} \sum_{b} \sum_{c} N^{[c, b]} \\
& \cdot\left[\gamma\left(r_{\mathrm{wr}}^{[c, b]}, r_{\mathrm{wl}}^{[c, b]}\right) \frac{d r_{\mathrm{wr}}^{[c, b]}}{d t}+\gamma\left(r_{\mathrm{wl}}^{[c, b]}, r_{\mathrm{wr}}^{[c, b]}\right) \frac{d r_{\mathrm{wl}}^{[c, b]}}{d t}\right]
\end{aligned}
$$

where

$\gamma\left(r_{0}, r_{1}\right)=\left(3 r_{0}^{4}+r_{1}^{4}-4 r_{0}^{3} r_{1}\right) \cdot\left(r_{0}-r_{1}\right)^{-2}$

stems from analytical differentiation of the integral in Eq. (16) and introduces the dependence on bin widths into Eq. (17). An assumption that $r_{\mathrm{wl}}^{[c, b]}<r_{\mathrm{wr}}^{[c, b]}$ is inherent in this formulation (cf. the discussion and a related proof of particle ordering principle in Gelbard, 1990). The same discretisation is applied to dry radii $r_{\mathrm{d}}$, and particle temperatures $T_{\mathrm{w}}$ introducing $r_{\mathrm{dl}}^{[c, b]}$ and $r_{\mathrm{dr}}^{[c, b]}$, and $T_{\mathrm{wl}}^{[c, b]}(t)$ and $T_{\mathrm{wr}}^{[c, b]}(t)$, respectively. The MOL is thus applied to calculate the evolution of $r_{\mathrm{w}}\left(r_{\mathrm{d}}, t\right)$ and $T_{\mathrm{w}}\left(r_{\mathrm{d}}, t\right)$ by discretising $r_{\mathrm{d}}$ and letting $t$ to be the only independent variable.
If the size spectra are discretised into adjacent bins then $T_{\mathrm{wr}}^{[c, b]}=T_{\mathrm{wl}}^{[c, b+1]}, r_{\mathrm{dr}}^{[c, b]}=r_{\mathrm{dl}}^{[c, b+1]}$ and $r_{\mathrm{wr}}^{[c, b]}=r_{\mathrm{wl}}^{[c, b+1]}$. Consequently, the state vector of the model assuming discretisation of the size-spectrum into $N_{b}$ adjacent bins and $N_{c}$ chemical components consists of:

- $N_{c} \cdot N_{b}$ constant concentrations $N^{[c, b]}$

- $N_{c} \cdot\left(N_{b}+1\right)$ constant dry radii $r_{\mathrm{dl}}^{[c, b]}$

- $N_{c} \cdot\left(N_{b}+1\right)$ variable wet radii $r_{\mathrm{wl}}^{[c, b]}$

- $N_{c} \cdot\left(N_{b}+1\right)$ variable temperatures $T_{\mathrm{wl}}^{[c, b]}$

- variable $p, T$ and $q_{\mathrm{v}}$

While still constant from the standpoint of the ODE solver, $N_{\mathrm{b}}, N^{[c, b]}$ and $r_{\mathrm{dl}}^{[c, b]}$ change during the grid refinement, and $N_{b}$ becomes $N_{b}^{[c]}$ (cf. Sect. 2.5).

The system of ODEs defines the derivatives of all the variables with respect to time as:

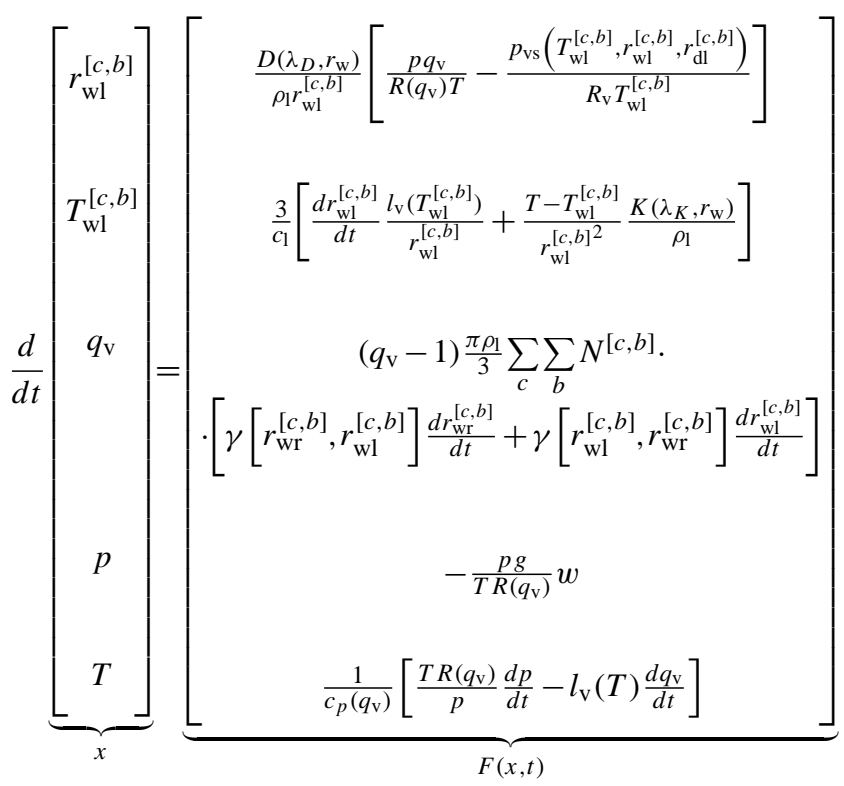

The first equation for the rate of change of the wet radii is the Fick's law (Eq. 4). The rate of change of particle temperatures (second equation in the system) is obtained by substituting $d Q$ defined in Eq. (6) into the Fourier's law (Eq. 5). The third equation in the system expressing the time derivative of specific humidity in the parcel is obtained by combining Eqs. (11) and (17). The last two equations defining the rate of change of pressure and temperature in the parcel correspond to Eqs. (2) and (1), respectively.

Particle growth is described here using separate equations for particle-temperature and particle-radius evolution (see e.g., Vesala et al., 1997), as opposed to a single explicit equation (the so-called Maxwell-Mason equation, Howell, 1949; Tsuji, 1950; Mason, 1957). The Maxwell-Mason approximation is available as an option in the program. 


\subsection{Initial conditions}

The initial dry-aerosol size spectra and their chemical composition, initial temperature, pressure, humidity and the vertical velocity profile are the key parameters for each model run.

PDFs of tropospheric aerosol are generally well represented using a trimodal log-normal distribution (Whitby, 1978). The initial spectra of dry aerosol are thus defined for each model run using (Williams and Loyalka, 1991, Eq. 1.22 therein):

$$
\begin{aligned}
& n_{\mathrm{d}}^{[c]}\left(r_{\mathrm{d}}\right) \\
& =\frac{1}{\rho} \sum_{m} \frac{N_{m}^{[c]}}{\sqrt{2 \pi} \ln \left(\sigma_{m}^{[c]}\right)} \frac{1}{r_{\mathrm{d}}} \exp \left[-\left(\frac{\ln \left(\frac{r_{\mathrm{d}}}{r_{m}^{[c]}}\right)}{\sqrt{2} \ln \left(\sigma_{m}^{[c]}\right)}\right)^{2}\right]
\end{aligned}
$$

where $N_{m}^{[c]}$ is the total concentration in the mode $m, \sigma_{m}^{[c]}$ is the geometric standard deviation of a mode, and $r_{m}^{[c]}$ is the mode radius (all defined separately for each chemical component $c$ ). $\quad N_{m}$ is generally reported as concentration (defined in terms of a unit volume, as opposed to unit mass as it is in case of specific concentration $n_{\mathrm{d}}$ ) hence the division by the air density $\rho$ in Eq. (20). The bins are initially equally spaced in logarithm of radius over the $1 \mathrm{~nm}-100 \mu \mathrm{m}$ range what ensures accurate representation of the log-normal shape of the initial spectra.

The initial spectra of wet aerosol are calculated by assuming an equilibrium state defined by

$$
\begin{aligned}
& \left.T_{\mathrm{wl}}^{[c]}\right|_{t=0}=\left.T_{\mathrm{wr}}^{[c]}\right|_{t=0}=T \\
& \left.\frac{d r_{\mathrm{wl}}^{[c]}}{d t}\right|_{t=0}=\left.\frac{d r_{\mathrm{wr}}^{[c]}}{d t}\right|_{t=0}=0
\end{aligned}
$$

that is effectively by the equality of the vapour pressure over the particle surface and the ambient vapour pressure.

The initial values of $T, p$ and $q_{\mathrm{v}}$ are chosen to describe the air properties slightly beneath the cloud base, i.e. at high relative humidity $(\mathrm{RH})$ but below saturation. High initial relative humidity translates to high initial water content it the particles. This assures that the mass of solute is small in comparison to the mass of the water, a prerequisite for the assumption that both the particle density and the surface tension coefficients are independent of particle composition.

\subsection{Numerical solution}

Integration of Eq. (19) without further approximations requires a numerical algorithm capable of solving a stiff ODE system (the stiffness of the system is confirmed e.g. by the significant inefficiency of the Adams-Moulton method with functional iteration). In addition, calculation of the initial wet spectra using an equilibrium condition defined by Eqs. (21) is not possible analytically. The latter problem is solved by employing an iterative root-bracketing procedure (using the Brent-Dekker method, cf. Sect. 2.6). The initial search interval for root-bracketing is defined using the dry radius for the lower bound, and the equilibrium value with the GibbsKelvin effect neglected for the upper bound.

The ODE system is solved using the variable-order, variable-step backward differentiation formula (BDF) as implemented in the CVODE solver (Cohen and Hindmarsh, 1996, cf. Sect. 2.6 herein). In each time-step (numbered by $i$ ) the ODE system $d x / d t=F(x, t)$ defined by Eq. (19) is integrated by finding a root of $f\left(x_{i}\right)$ :

$f\left(x_{i}\right)=\sum_{k=1}^{h} \alpha_{i, k} x_{i-k}+\left(t_{i}-t_{i-1}\right) \beta_{i} F\left(x_{i}, t_{i}\right)-x_{i}$

using the Newton-Raphson iteration (here $h$ varies between 1 and 5, and defines the order of the method at the current timestep, and $\alpha_{i, k}$ and $\beta_{i}$ are variable coefficients). The iteration (with steps numbered by $j$ ) is of the following form:

$x_{i}^{j+1}=x_{i}^{j}-\frac{f\left(x_{i}\right)}{f^{\prime}\left(x_{i}\right)}=x_{i}^{j}+\frac{f\left(x_{i}\right)}{1-\left(t_{i}-t_{i-1}\right) \beta_{i} \frac{\partial F}{\partial x}}$

The Jacobian matrix $\partial F / \partial x$ is updated at least once every twentieth time-step. The Jacobian is approximated by multiple evaluations of the right-hand side of Eq. (19) using the current, and slightly perturbed values of $x$.

The CVODE solver adaptively chooses time-step according to the desired accuracy to be achieved in each step of integration (relative tolerance of $1 \times 10^{-8}$ and zero absolute tolerance was used in the calculations presented here). In addition, the solver is instructed to shorten the time-step if an unphysical condition is detected during evaluation of the system right-hand side $F(x, t)$ (e.g. if a positively-defined quantity has a negative value or if the left edge of a bin outruns its right edge).

The right-hand side of the ODE system is evaluated in the order presented in Eq. (19). The integration is performed until a desired time (altitude) is passed, and an interpolated set of values for this time (altitude) is calculated and returned.

After each successful integration step, a spectrumrefinement procedure is carried out, if necessary, and in that case the integration over the last time-step is repeated. The conditions for triggering the grid-refinement are defined and discussed in the following subsection. Each refinement causes a change of the length of $x$, which in turn results in reducing the current order $h$ to unity, and re-evaluation of the Jacobian matrix.

A solution of the problem in context of cloudmicrophysical studies is a set of properties of the droplet spectrum such as cloud droplet number concentration (CDNC), liquid water content (LWC), average droplet radius $(\langle r\rangle)$, the standard deviation of the size spectrum $\left(\sigma_{\mathrm{r}}\right)$ and effective radius $\left(r_{\text {eff }}\right)$. The $\mathrm{k}$-th moment of the droplet spectrum is evaluated, taking into account that the left-most 
(and right-most) bins may fall only partially in the given droplet size range, using:

$\left\langle r_{\mathrm{w}}^{k}\right\rangle=Z_{k} / Z_{0}$

where

$Z_{k}=\sum_{c} \sum_{b} \frac{N^{[c, b]}}{r_{\mathrm{wr}}^{[c, b]}-r_{\mathrm{wl}}^{[c, b]}} \frac{r_{b}-r_{a}}{r_{\mathrm{wr}}^{[c, b]}-r_{\mathrm{wl}}^{[c, b]}} \frac{r_{b}^{k+1}-r_{a}^{k+1}}{k+1}$

where $r_{a}=\max \left(r_{\min }, r_{\mathrm{wl}}^{[c, b]}\right), r_{b}=\min \left(r_{\max }, r_{\mathrm{wr}}^{[c, b]}\right) ; r_{\min }$ was set at $1 \mu \mathrm{m}$ and $r_{\max }$ at $25 \mu \mathrm{m}$. Consequently:

$-\mathrm{CDNC}=\rho Z_{0}$

- $\mathrm{LWC}=4 \rho \pi \rho_{1} Z_{3} / 3$

- $\sigma_{\mathrm{r}}=\sqrt{Z_{2} / Z_{0}-\left(Z_{1} / Z_{0}\right)^{2}}$

$-r_{\text {eff }}=Z_{3} / Z_{2}$

\subsection{The adaptive size-spectrum discretisation scheme}

The key task of the adaptive discretisation scheme is to control the accuracy of the discretisation by splitting any overly wide bins into several smaller bins while the ODE system is integrated. Using the MOL nomenclature (Wouwer et al., 2001, Sect. 1.3 therein) it is thus an $h$-refinement of the spatial grid. Insertion of new bins takes place at discrete time levels only, namely when the ODE solver reaches its next internal time-step. Consequently, the grid adaptation procedure is decoupled from the ODE integration and as such the static girding is employed. The method utilises the so-called full restart as the ODE solver is reinitialised after each refinement event, and restarts with the lowest order. The restart and the reduction of the method order is a consequence of changing the length of the model state vector $x$.

The criterion for triggering the division of a given bin is defined as follows. Bin splitting happens whenever the ratio of the logarithm of the width of a given bin to its initial value reaches a certain limit. The limit was set at 2 for most of the simulations discussed in the text (save for the case of urban aerosol where 1.8 was used, cf. Sect. 3.3), meaning that no bin was allowed to double its width when viewed in logarithmic scale (the previous step of the solver is repeated each time new bins are added). Smaller limits cause the algorithm to carry out the refinement earlier in time and hence increase the computational effort. Larger limits delay the refinement and at the same time increase the uncertainty inherent to the interpolation performed to calculate the particle temperatures and dry/wet radii at the edges of the newly created bins. No refinement takes place when the particle concentration in a given bin is below a certain level hereinafter referred to as the tolerance.

Each refinement event causes a full-restart of the ODE solver which, in turn, causes the solver to reduce the order, tighten its time-step, re-evaluate the Jacobian matrix, and consequently slow down the computations. For this reason, the number of bins into which a bin is split is chosen in a way ensuring no further splitting of any of the newly created bins will occur. The number of new bins added is thus chosen by dividing $N^{[c, b]}$ by the tolerance. The new bins are spaced linearly in radius, and hence the specific concentration in each of the new bins is equal. The values of particle temperature and particle dry/wet radii at the newly introduced bin boundaries are linearly interpolated from the values at the boundaries of the bin being split.

The refinement criterion and the refinement procedure are local to a given bin and thus different bins may be split at different times during the integration.

In principle, the presented approach replaces the single parameter of the discretisation, the number of bins, with two new parameters: the initial number of bins and the tolerance. The former determines the uncertainty related to the discretisation of the initial condition (initial dry radii). The later controls the uncertainty associated with the final spectrum, and has a physical meaning, being the highest number of particles allowed to reside in a bin laying in between the two modes of the final aerosol spectrum (i.e. modes of activated and non-activated particles).

\subsection{Implementation of the model}

The program is implemented in an object-oriented manner in $\mathrm{C}++$. The implementation is built upon the Boost.Units framework for dimensional analysis of the code at compilation time (Schabel and Watanabe, 2008) hence a physical unit is assigned to every variable/expression in the code with no performance penalty. The GNU Scientific Library (Galassi et al., 2009) is used for root-bracketing using the BrentDekker method (cf. Sect. 2.4 herein and Sect. 33.8 therein). The ODE system is solved using the CVODE solver (Cohen and Hindmarsh, 1996) interfaced through the SUNDIALS package (Hindmarsh et al., 2005). CVODE is a C-written successor to the Fortran-written VODE solver and a close relative of the LSODE solver. LSODE was used e.g. in Ghan et al. (1998), Nenes et al. (2001b) and Romakkaniemi et al. (2006) while two out of five models compared in Kreidenweis et al. (2003) and the model of Debry et al. (2007) were based on VODE.

The source code of the program is available as an electronic supplement of this paper and is released under the GNU General Public License. All model parameters are passed using UNIX-like command-line options. Toggling such settings of the model as transition régime corrections, the Gibbs-Kelvin effect or the adaptivity do not require recompilation. Similarly, altering the numerical solution parameters such as the tolerances or switching from BDF to Adams-Moulton method for ODE integration is possible using command-line options. A web-based interface (written in HTML/PHP) allowing alteration of all model options, 
visualisation of single simulation results, as well as control of parallel runs of simulations with different input parameters is included.

\section{Example results}

\subsection{Example run without adaptivity: sea-salt/sulphate competition in marine aerosol activation}

Ghan et al. (1998) presented an analysis of relative importance of sea-salt and sulphate particles during CCN activation. The study was based on a series of simulations using a moving-sectional model of $\mathrm{CCN}$ activation. We use here a similar set-up for discussing an example model run without adaptivity and relatively low spectral resolution (45 bins over the $1 \mathrm{~nm}-100 \mu \mathrm{m}$ radius range).

In the set-up the initial aerosol content of the air parcel is described by a sum of a single-mode log-normal distribution of ammonium sulphate aerosol, and a tri-modal log-normal distribution of sodium chloride aerosol. The parameters of all modes are listed in Table 1 and are based on measurementdata fits summarised in O'Dowd et al. (1997, values for horizontal wind speed of $15 \mathrm{~m} \mathrm{~s}^{-1}$ were used ).

A steady updraft $w=0.25 \mathrm{~m} \mathrm{~s}^{-1}$ is driving the changes in the parcel's temperature, pressure, and relative humidity which are initially set at $280 \mathrm{~K}, 1000 \mathrm{hPa}$ and $99 \%$, respectively. The integration is performed for $250 \mathrm{~s}$.

A summary of evolution of the aerosol spectra is presented in Fig. 1 (see figure caption for details). The shift towards larger sizes of the initial wet spectra (green lines in Fig. 1a) with respect to the initial dry spectra (red lines) reflects the growth of particles up to $\mathrm{RH}=99 \%$ calculated assuming equilibrium condition (cf. O'Dowd et al., 1997, Fig. 4 therein). Further growth of the aerosol is calculated resolving the diffusion kinetics, and leads to activation of $\mathrm{CCN}$ and formation of droplets (peaks on right-hand side of the final blue spectra in Fig. 1b). The final spectra of both sulphate and sea-salt particles are distinctly bi-modal. The largeparticle mode corresponds to cloud droplets, and is visible in both sulphate and sea-salt distribution. The small-particle mode corresponds to unactivated particles. The largest droplets were formed on sea-salt aerosol. For both aerosol components, the region of spectra between the two modes of the final PDFs is represented with a single bin spanning over an order of magnitude in radius. This very section(s) is hereinafter referred to as the critical section(s) following Korhonen et al. (2005).

Figure 2 presents the time-evolution of particle sizes, particle temperatures (colour scale representing $T_{\mathrm{w}}-T$ ), and the time/height profile of relative humidity. Wet radii corresponding to the two chemical components considered are plotted using circles and diamonds. The differences in wet radii for the same dry size (i.e. the differences arising from the differences in water activity for sea-salt and sulphate solutions) are most pronounced in the left-hand
Table 1. Aerosol distributions used in the example model run discussed in Sect. 3.1. Data after O'Dowd et al. (1997), as used in Ghan et al. (1998).

\begin{tabular}{lcccc}
\hline Mode & Solute & $\begin{array}{c}N_{m} \\
{\left[\mathrm{~cm}^{-3}\right]}\end{array}$ & $\begin{array}{c}r_{m} \\
{[\mu \mathrm{m}]}\end{array}$ & $\begin{array}{c}\sigma_{m} \\
{[1]}\end{array}$ \\
\hline Film drop & $\mathrm{NaCl}$ & 51.1 & 0.10 & 1.90 \\
Jet drop & $\mathrm{NaCl}$ & 2.21 & 1.00 & 2.00 \\
Spume drop & $\mathrm{NaCl}$ & 0.00001 & 6.00 & 3.00 \\
Accumulation & $\left(\mathrm{NH}_{4}\right)_{2} \mathrm{SO}_{4}$ & 100 & 0.08 & 1.45 \\
\hline
\end{tabular}

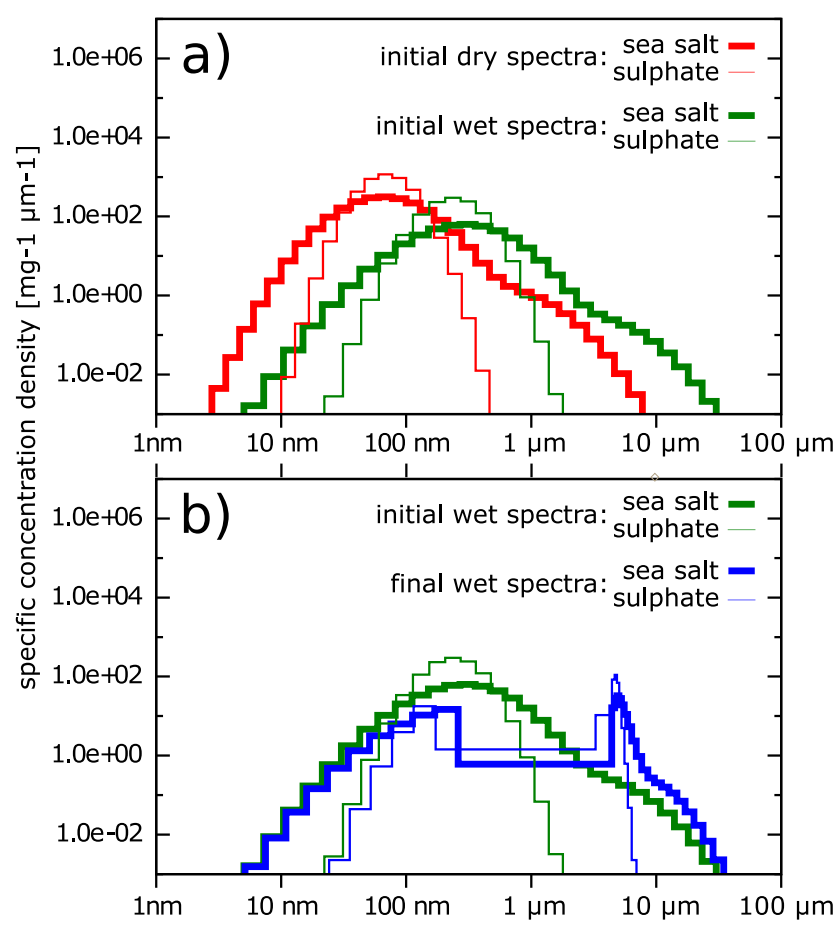

Fig. 1. A summary of aerosol size spectra evolution as calculated in the model run discussed in Sect. 3.1. The four data sets plotted in plot (a) correspond to the initial dry (red colour), and the initial wet (green colour) spectra for sea-salt (thin lines) and sulphate (thick lines) aerosol. In plot (b) the initial wet spectrum (green colour) is shown again, together with the final wet spectrum (blue colour).

side of the plot (i.e. particles of less than $10 \mathrm{~nm}$ in radius). Elsewhere, the two symbols (i.e. circles and diamond) overlap. The symbols are drawn every fiftieth time-step of the solver, and what follows the time-step adjustments made by the solver may be observed.

Four phases of the process can be distinguished (Howell, 1949). First, the particles grow slowly approximately until the relative humidity reaches $100 \%$. From then on, the relative humidity does not fall below $100 \%$ and hence all subsequent phases occur at supersaturation with respect to the plane surface of pure water. The second phase is 


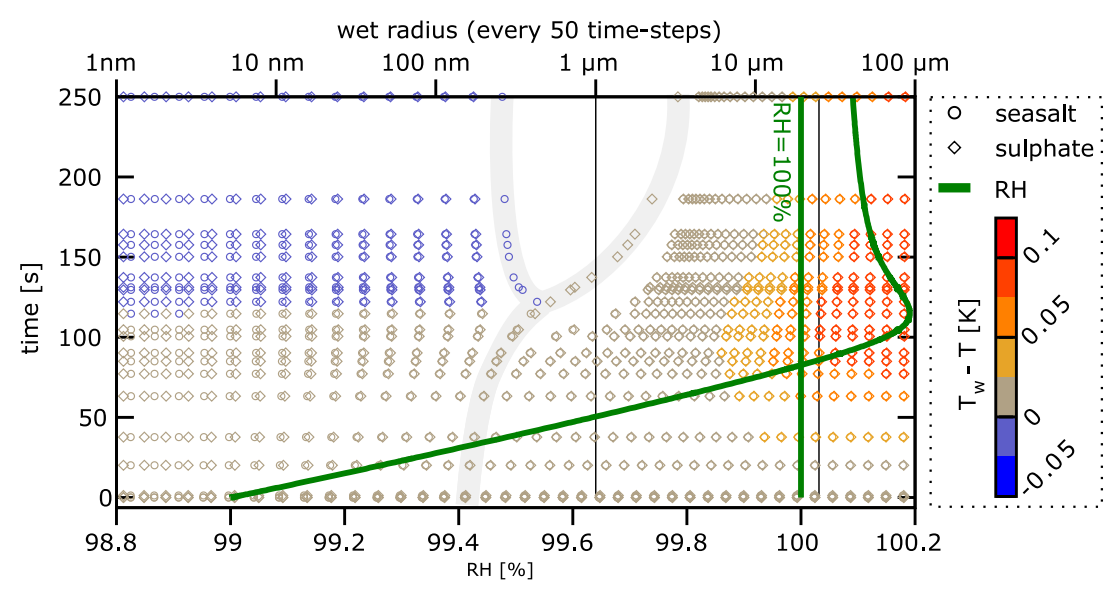

Fig. 2. Evolution of the aerosol spectra (symbols) and the relative humidity (green curve) as calculated in the model run discussed in Sect. 3.1. Wet radii at bin boundaries are drawn every 50 time-steps. Circles and diamonds correspond to sea-salt and sulphate aerosol, respectively. Colour of the symbols indicate the difference between the temperatures of particles and the surrounding air. The two dark-grey vertical lines at 1 and $25 \mu \mathrm{m}$ indicate the region of the spectra used for calculating the moments of the droplet spectrum, as defined by Eq. (25). The thick light-grey bifurcated line in the background is drawn to highlight the two bin boundaries of the same dry radius which undergo markedly different evolution for sulphate and sea-salt aerosol (discussed in the text).

characterised by a rapid growth of particles in the $0.5-5 \mu \mathrm{m}$ range, and continuous increase of the relative humidity until reaching a maximum value of $100.2 \%$. In the third phase, occurring roughly from $120 \mathrm{~s}$ until $150 \mathrm{~s}$, the rate of growth of particles stabilises throughout the whole spectrum, with the exception of the region separating the unactivated and activated modes. There, one of the bin-boundaries undergoes a different evolution for sulphate and sea-salt aerosol, initially having equal volume of dry material (highlighted with the thick light-grey bifurcated line in the background in Fig. 2). The highlighted bin boundary in the sulphate spectrum becomes the smallest one in the activated part of the spectrum, while the one of the sea-salt aerosol is the largest one in the unactivated part of the spectrum. The relative humidity decreases during the third phase. Finally, the fourth phase of the growth represents a quasi-equilibrium state with activated droplets steadily growing at almost constant relative humidity.

The characteristics of the droplet spectra (spectrum moments calculated over the $1 \mu \mathrm{m}-25 \mu \mathrm{m}$ radius range) are presented in Fig. 3. The shapes of both spectra (sea-salt and sulphate solution droplets) are plotted at six intermediate altitudes (histograms constructed with thick and thin blue lines, respectively). The droplet specific number concentration (turquoise line) increases till about $140 \mathrm{~s}(35 \mathrm{~m})$, and stays constant afterwards. The mean radius (thick orange line) increases continuously with height from the onset of droplet formation till the end of the model run. The standard deviation of the droplet radius (thin orange lines) stays approximately constant. The droplets formed on sulphate aerosol dominate in the small-size part of the spectrum, while the sea-salt aerosol took part in formation of the largest droplets.

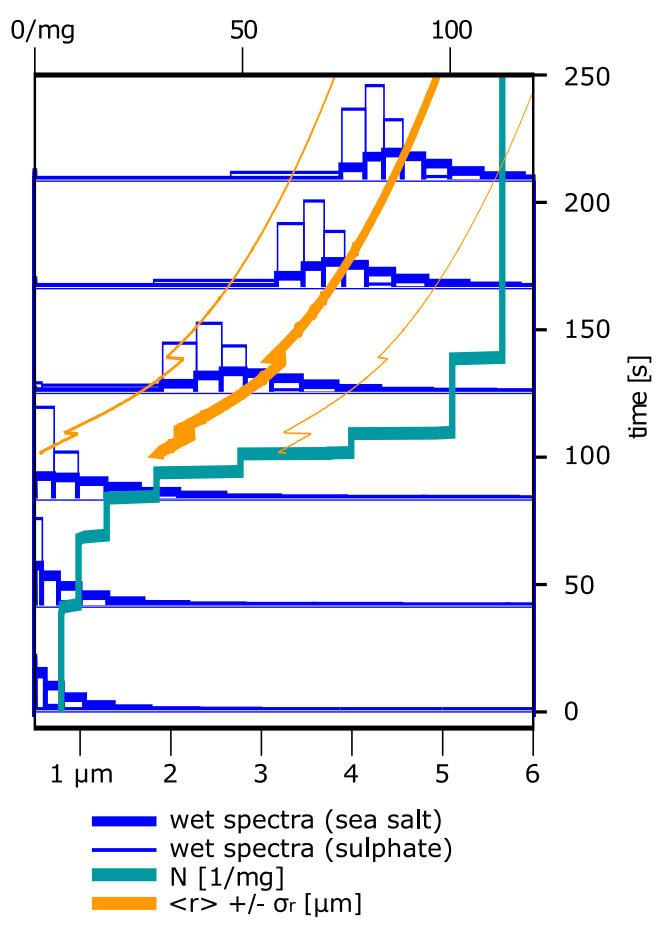

Fig. 3. A summary of the evolution of droplet spectrum as calculated in the model run discussed in Sect. 3.1. The wet spectra are drawn at six selected time-steps using separate histograms for sulphate (thin blue lines) and sea-salt (thick blue lines). The vertical scaling factor is the same for all twelve histograms, and has an arbitrary value. The thick orange line denotes average droplet radius, while the two surrounding thin orange lines represent the width of the spectrum $\left( \pm \sigma_{\mathrm{r}}\right)$. Both the average radius and the standard deviation are shown only after the specific concentration reaches $50 \mathrm{mg}^{-1}$. The turquoise line denotes specific droplet concentration (units at the top axis). 


\subsection{Sensitivity to the discretisation resolution (without adaptivity)}

Apart from the physical parameters of the model (such as vertical velocity profile), and the initial values of model variables (such as initial temperature and the dry aerosol spectra), the model results depend on parameters controlling the discretisation scheme and the integration process. As pointed out in Kreidenweis et al. (2003) the droplet number concentrations obtained with models relying on the movingsectional technique are sensitive to the number of bins used for the discretisation of the aerosol spectra. To assess the degree to which the choice of the number of bins used to represent the initial spectrum influences the results, a set of simulations run with different number of bins is compared. The variability of the results due to changes in discretisation parameter is compared with the variability associated with the aerosol physical and chemical properties, and the vertical air velocity.

Four tri-modal aerosol distributions corresponding to properties of aerosol of different air-mass types are taken into account. Their parameters are listed in Table 2 and are based on the marine, clean continental, average background and urban cases reported in Whitby (1978). For each distribution, a nuclei mode, an accumulation mode, and a coarse mode is defined. The spectra are assumed to represent the sizes of dry particles. This is the set of cases used in Nenes et al. (2001b) for studying the influence of aerosol characteristics on cloud radiative properties using a moving-sectional model of $\mathrm{CCN}$ activation.

For each of the considered initial aerosol size distributions the calculations are carried out separately assuming pure ammonium sulphate and pure sodium chloride aerosol, and for three different updraft speeds, namely $0.25,1$ and $4 \mathrm{~m} \mathrm{~s}^{-1}$. Calculations are performed until reaching $125 \mathrm{~m}$. Each set-up (defined by one of the four size-spectra, one of the two chemical compositions, and one of the three vertical velocities) is tested with 54 different numbers of bins ranging from 30 to 300, with a step of 5 . All other model parameters are defined as in the example run described in Sect. 3.1.

Figure 4 presents the results from all 1296 model runs. Six quantities are compared, out of which five represent the final values reached at the altitude of $125 \mathrm{~m}$ above the initial level: the droplet concentration $\mathrm{CDNC}$, the mean radius of the droplets $\langle r\rangle$, the standard deviation of the droplet radius $\sigma_{\mathrm{r}}$, the effective radius $r_{\text {eff }}$ and the liquid water content LWC. The sixth quantity is the maximum supersaturation $S_{\max }=\max (\mathrm{RH}-1)$ encountered during the model run, expressed in percent. It is evident that the model results are sensitive to the number of bins used to represent the initial spectra of aerosol. The maximum supersaturation is the only quantity not exhibiting significant variation. The variability associated with the changes in the number of bins is in some cases stronger than that due to different chemical composition or updraft velocity (e.g. $\sigma_{\mathrm{r}}$ in the marine case).
Table 2. Aerosol distributions used in the model runs presented in Sects. 3.2-3.3. Data after Whitby (1978), as used in Nenes et al. (2001b).

\begin{tabular}{lccc}
\hline $\begin{array}{l}\text { Spectrum } \\
\text { (mode) }\end{array}$ & $\begin{array}{c}N_{m} \\
{\left[\mathrm{~cm}^{-3}\right]}\end{array}$ & $\begin{array}{c}r_{m} \\
{[\mu \mathrm{m}]}\end{array}$ & $\begin{array}{c}\sigma_{m} \\
{[1]}\end{array}$ \\
\hline Marine (nuclei) & 340 & 0.005 & 1.6 \\
Marine (accumulation) & 60 & 0.035 & 2.0 \\
Marine (coarse) & 3.1 & 0.31 & 2.7 \\
Clean continental (nuclei) & 1000 & 0.008 & 1.6 \\
Clean conti. (accumulation) & 800 & 0.034 & 2.1 \\
Clean conti. (coarse) & 0.72 & 0.46 & 2.2 \\
Average background (nuclei) & 6400 & 0.008 & 1.7 \\
Average bg. (accumulation) & 2300 & 0.038 & 2.0 \\
Average bg. (coarse) & 3.2 & 0.51 & 2.16 \\
Urban (nuclei) & 106000 & 0.007 & 1.8 \\
Urban (accumulation) & 32000 & 0.027 & 2.16 \\
Urban (coarse) & 0.43 & 0.43 & 2.21 \\
\hline
\end{tabular}

Gradual increase of the number of bins does lead to the convergence of the result to an asymptotic value; however, arguably 300 bins is not a sufficient number in some cases. Clearly, the results obtained with less than 100-150 bins are characterised by significant uncertainty.

The spread of the obtained CDNC values is roughly in line with results reported in Kreidenweis et al. (2003) and Korhonen et al. (2005). While the differences in the model formulations, and the differences in model set-ups rule out direct comparison of the results, it is worth to mention several of observations from the two mentioned studies. In both cases the focus was given to the droplet number concentration. Kreidenweis et al. (2003, Par. 22 and Fig. 8 therein) compared results from four different models, running them with different number of bins ranging from 20 to 100 . The bins were spaced equally in logarithm of radius and in all cases covered at least two decades of the $1 \mathrm{~nm}-10 \mu \mathrm{m}$ size range. The variability of droplet number concentrations was observed for all of the models. The discrepancies between the results obtained with the same model but with different number of bins reached ca. $10 \%$. Korhonen et al. (2005) compared results obtained using five different activation schemes run at low spectral resolution (10 bins within the $10 \mathrm{~nm}-1.5 \mu \mathrm{m}$ range) with a highresolution run in which 500 bins were used. The variations were analysed separately for marine, rural, and urban aerosol, and for a variety of vertical velocities (all below $1 \mathrm{~m} \mathrm{~s}^{-1}$ ). Predictions of the most accurate low-resolution models differed from the high-resolution calculations by roughly, up to $1 \%, 10 \%$ and $50 \%$ for marine, rural, and urban aerosol, respectively (Korhonen et al., 2005, Fig. 3 therein). 

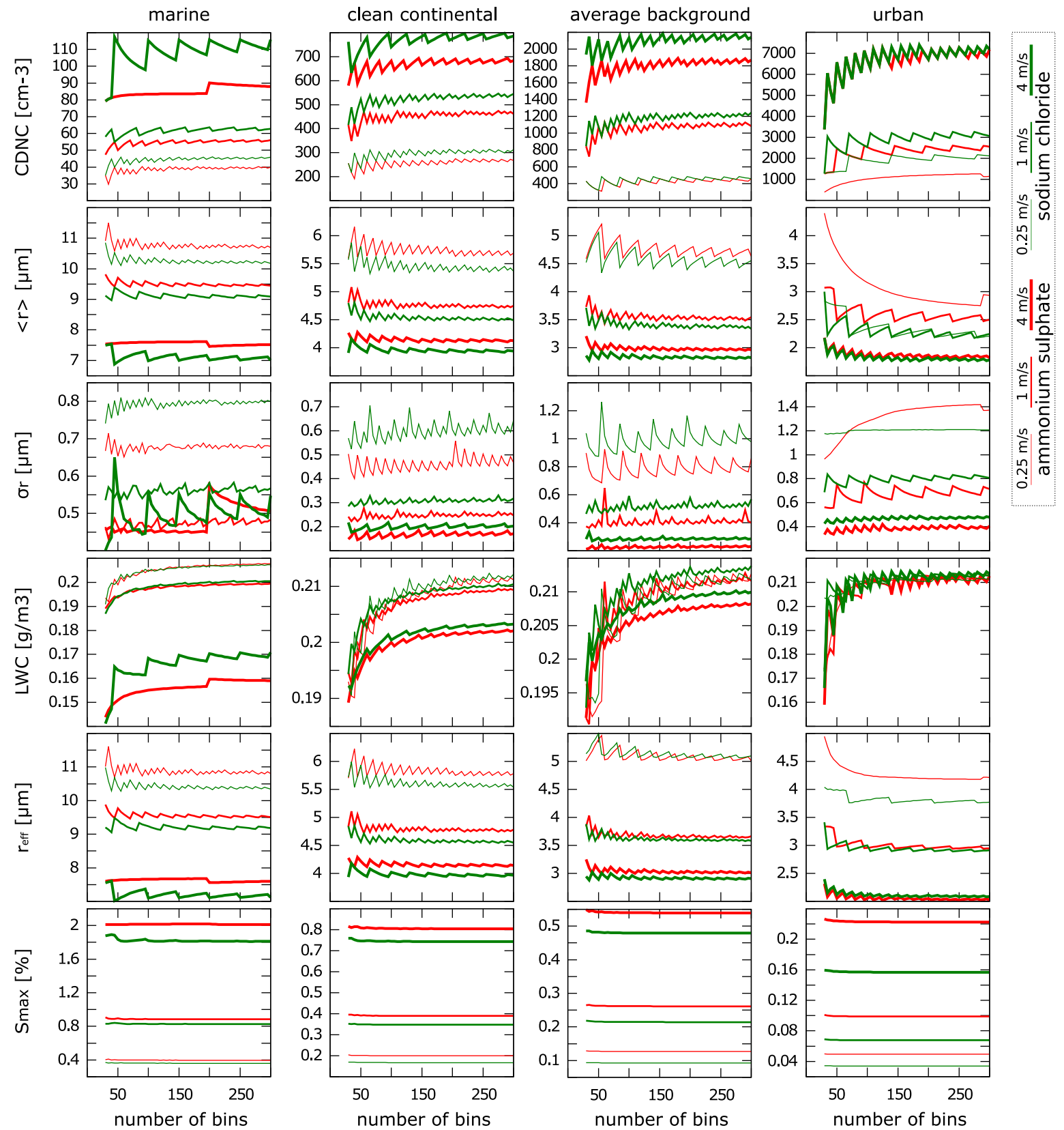

Fig. 4. A summary of results obtained without adaptivity in the 1296 model runs discussed in Sect. 3.2 (see text for details) plotted as a function of the number of bins. The lines are drawn by connecting points every 5 bins. The width and colour of a line correspond to the vertical velocity and solute, respectively (cf. the key in the top-right corner of the figure). Each of the four columns of plots corresponds to a different initial aerosol size spectrum (i.e. marine, clean continental, average background and urban), all plots in a column share the x-axis. Each of the top five rows of plots corresponds to a droplet spectrum parameter (i.e. CDNC, $<r>, \sigma_{\mathrm{r}}$, LWC and $r_{\mathrm{eff}}$ ). The bottom row of plots corresponds to the maximum supersaturation. The ranges of the y-axes differ. Figure 5 presents analogous results obtained with adaptivity (with maximum supersaturation plots omitted).

The problem of the sensitivity of the moving-sectional model results to the spectrum discretisation resolution was also discussed in Takeda and Kuba (1982, Sect. 2.5 therein) where the authors mention large influence of the number of particles in a critical section on the total number of activated cloud droplets, as well as broadening of the cloud droplet size spectrum with increasing number of bins used. Ghan et al. (1998) used bins of equal number of particles, as opposed to the present logarithmic layout, effectively increasing the discretisation resolution near the critical section(s). 

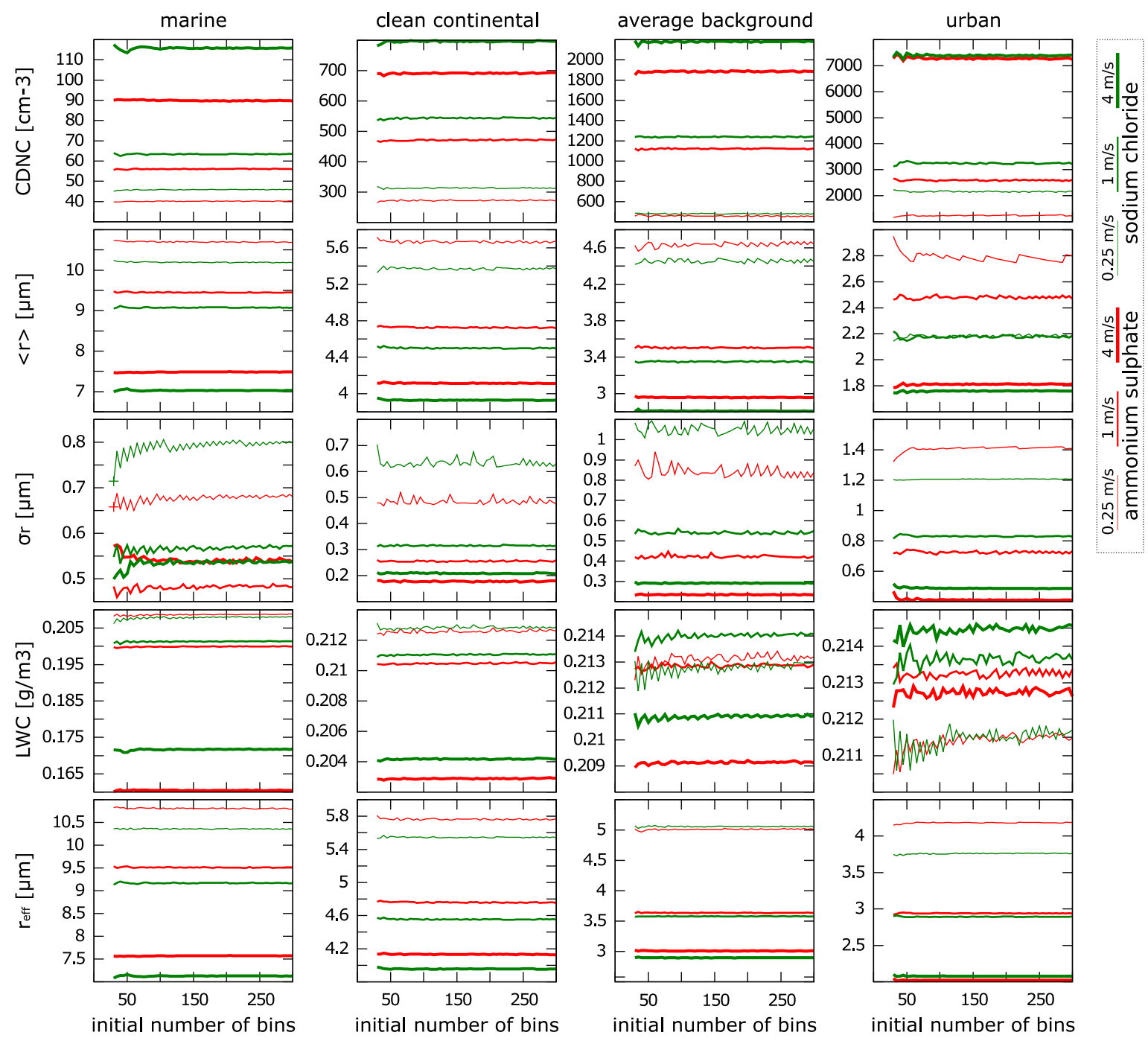

Fig. 5. A summary of results obtained with adaptivity in the 1296 model runs discussed in Sect. 3.3 (see text for details). Figure 4 presents analogous results obtained without adaptivity (see caption for explanation of the plot elements).

\subsection{Example results with adaptivity}

The same series of simulations as presented in the previous section was repeated with adaptivity. The tolerances were set to $\min \left(0.5 \% \cdot N_{m}, 50 \mathrm{mg}^{-1}\right)$ using $N_{m}$ of the accumulation mode (see Table 2) giving $0.3 \mathrm{mg}^{-1}, 4 \mathrm{mg}^{-1}, 11.5 \mathrm{mg}^{-1}$ and $50 \mathrm{mg}^{-1}$ for marine, clean continental, average background and urban cases, respectively. The results of multiple simulations with adaptivity are summarised in Fig. 5 intended for direct comparison with Fig. 4. The previously observed variability of the results with varying number of bins is visibly suppressed confirming the efficacy of the proposed method. The quality of the results (i.e. the stability with regard to the number of initial bins) obtained with low initial number of bins is significantly enhanced, in particular in the case of LWC. This suggests that introduction of the adaptivity helps the model to correctly resolve both droplet mass- and droplet number-related quantities, even though the model is formulated using particle number distributions. Both the effective radius $r_{\text {eff }}$ and cloud droplet number concentration CDNC do not exhibit virtually any variability (both being the focus of studies of cloud albedo and climate impacts, cf. e.g., Brenguier et al., 2000, and references therein). Comparison of Figs. 4 and 5 confirms that (i) the sensitivity of the model-predicted values of CDNC to number of bins reported by Kreidenweis et al. (2003) and Korhonen et al. (2005) is related to the poor representation of the spectrum shape near the critical section(s); (ii) the adaptive discretisation scheme correctly identifies the critical section(s); (iii) the proposed refinement strategy helps to limit the uncertainty of the results.

Figure 6 summarises the relation between the initial and final number of bins, and thus provides a brief estimate of the memory/CPU footprint of the adaptive 

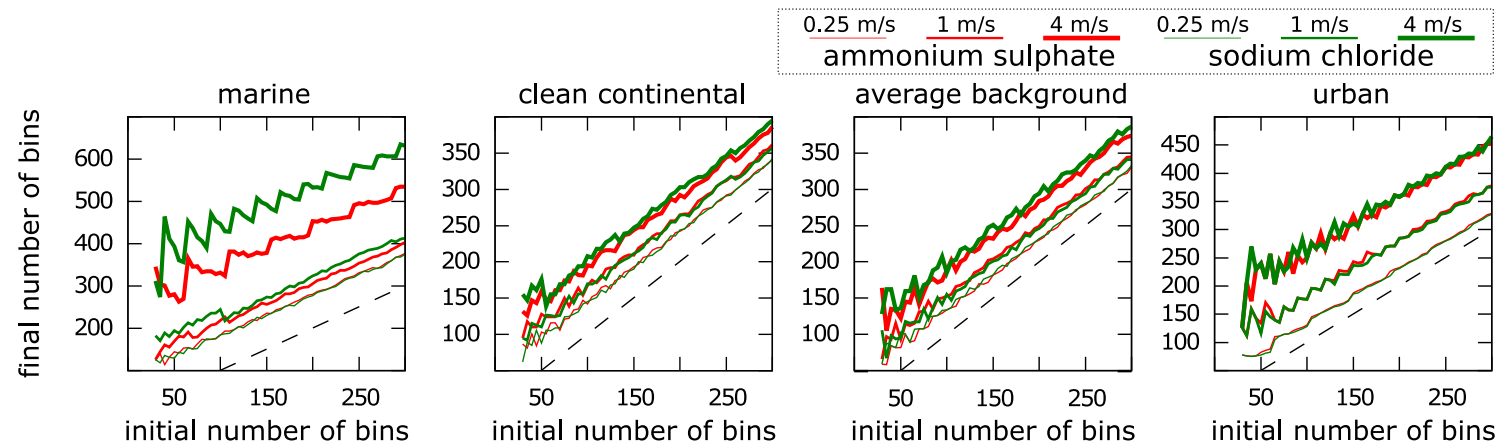

Fig. 6. Final number of bins plotted as a function of the initial number of bins for the model runs with adaptivity presented in Fig. 5 and discussed in Sect. 3.3. Dashed lines in the plot are 1:1 lines representing cases without adaptivity. Consult the caption of Fig. 4 for explanation of the plot elements.

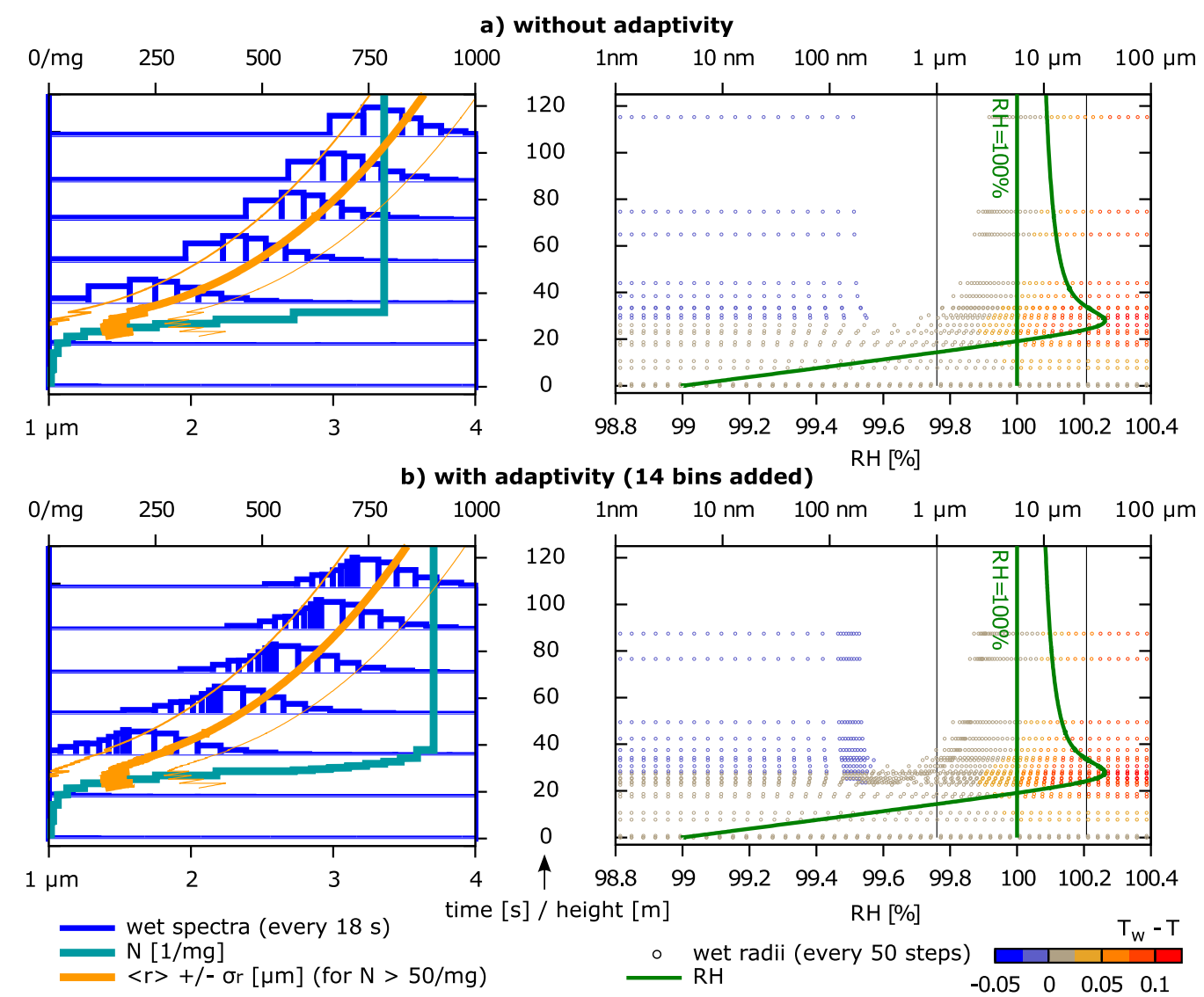

Fig. 7. A comparison of aerosol spectra evolution as calculated in two model runs with adaptivity toggled off (a) and on (b). See captions of Figs. 1-3 for description of the plot elements. Figure discussed in Sect. 3.3.

refinement scheme. The key observation is that the final number of bins corresponding to ca. 50 bins on the abscissa (i.e. roughly the number of bins needed to obtain convergence with adaptivity) is, in general, lower than the number of bins needed to obtain convergence without adaptivity. Consequently, the method offers a reduction of computational effort needed to obtain results of a given precision.
An in-detail comparison of one of the simulations presented in Figs. 4 and 5 is presented in Fig. 7a (without adaptivity) and $7 \mathrm{~b}$ (with adaptivity). The vertical velocity was set at $1 \mathrm{~m} \mathrm{~s}^{-1}$, the aerosol size spectrum was initialised with the average background distribution, and the composition was assumed to be pure ammonium sulphate. To enhance the readability of the figure by lowering the number of bins, the initial number of bins was set at 
55 , and the tolerance was decreased to $46 \mathrm{mg}^{-1}$. During the simulation with adaptivity 14 bins were added to the spectrum. There are two most evident differences among the plots in Fig. 7a and b. First, the final concentration calculated with adaptivity is about $15 \%$ higher, and consequently the predicted average droplet radius is smaller. Second, the shape of the spectra at different heights is asymmetric for the case without adaptivity.

Enabling adaptivity, and thus increasing the resolution of the discretisation in the very region of the spectrum where the droplet-growth is most vigorous, allows the model to resolve the shape of the left-hand side slope of the droplet spectrum. This suggests that the asymmetry of the droplet spectrum near cloud base, predicted by the model without adaptivity, is a numerical artefact. Finding support for this observation in experimental data is difficult as most of the cloud droplet spectrometers nowadays are optical instruments which, for physical reasons, cannot sense the smallest (i.e. $<1.5 \mu \mathrm{m}$ in radius) droplets (see e.g., Fig. 10a in Lawson and Blyth, 1998, presenting the cloud spectra $50 \mathrm{~m}$ above cloud base as measured by three different instruments).

The ability of the model to faithfully resolve the spectrum shape at the very onset of droplet growth is of potential importance for the development of parameterisations of the activation process for use in cloud-resolving hydrodynamical models (see e.g., the discussion in Grabowski and Wang, 2009, where the authors underline the need for parameterising the initial width of the spectrum of activated droplets).

Comparison of the right-hand side panels of Fig. 7a and $b$ suggests that the adaptivity contributes as well to a better representation of the transition-régime corrections in the model. The increase of the number of bins near $100 \mathrm{~nm}$ results in probing the transition-régime interpolation formulæ at denser intervals.

\section{Summary and outlook}

This paper discussed a numerical method for studying the kinetics of aerosol growth by vapour condensation in the context of CCN activation. A simple yet robust air-parcel model of droplet formation utilising the adaptive method of lines was formulated. Implementation of the model was discussed and its source code is available as an electronic supplement of the paper. Example results for single- and multi-component aerosol, with- and without adaptivity, for different vertical velocities, and different initial aerosol spectra were presented.
The key advantages of the introduced grid refinement method are (i) the suppression of bogus sensitivity of the model results to the discretisation parameters when working in low resolution; (ii) the introduction of physically-based uncertainty-related parameters controlling the spectrum discretisation independently of the resolution of model input; (iii) the enhancement in resolution of the shape of the left edge of the model-predicted droplet spectrum; (iv) the reduction of computational effort needed to obtain results of a given precision. The discussion of results obtained without adaptivity constitutes an assessment of the uncertainty of results obtained using classical MOL (see Fig. 5).

Presented method is potentially applicable to numerous fields of aerosol/hydrosol-related research where movingsectional models of aerosol growth are used, including (i) studies of closure among the $\mathrm{CCN}$ activation theory and in-situ measurements of cloud properties (e.g., Snider et al., 2003); (ii) design and calibration of aerosol instruments (e.g., Nenes et al., 2001a); (iii) research on the nucleation of aerosol in the atmosphere (e.g., Anttila et al., 2004); iv) estimations of the impact of aerosol properties and the kinetics of its growth on cloud albedo (e.g., Nenes et al., 2001b) and the related assessments of geoengineering techniques for global warming mitigation (e.g., Bower et al., 2006); (v) investigations on cloud processing of aerosol (e.g., Romakkaniemi et al., 2006); (vi) construction and evaluation of parameterisations to be employed in hydrodynamical models run at resolutions where $\mathrm{CCN}$ activation is a sub-scale process (e.g., Feingold and Heymsfield, 1992). Further studies underway are aimed at validating the model with aircraft measurements, and at enhancing the representation of links between particle growth kinetics and its composition. The implemented logic for efficiently handling variable number of bins shall be a valuable component for implementing an accurate treatment of the coagulation process using the movingsectional approach. Results of these studies will be reported in future publications. 


\section{Appendix A}

List of symbols.

\begin{tabular}{|c|c|c|}
\hline Symbol & SI unit & Description \\
\hline$\alpha, \beta$ & [1] & coefficients in the BDF formula \\
\hline$\gamma$ & {$\left[\mathrm{m}^{2}\right]$} & helper symbol in Eqs. 17 and 18 \\
\hline$\rho$ & {$\left[\mathrm{kg} \mathrm{m}^{-3}\right]$} & density of moist air in the parcel \\
\hline$\rho_{\mathrm{l}}=1000$ & {$\left[\mathrm{~kg} \mathrm{~m}^{-3}\right]$} & density of liquid water \\
\hline$\rho_{\mathrm{V}}$ & {$\left[\mathrm{kg} \mathrm{m}^{-3}\right]$} & density of water vapour in the parcel \\
\hline$\sigma=0.072$ & {$\left[\mathrm{~J} \mathrm{~m}^{-2}\right]$} & surface tension coefficient of water \\
\hline$\sigma_{m}, \sigma_{m}^{[c]}$ & [1] & geometric standard deviation of a log-normal mode \\
\hline$\sigma_{\mathrm{r}}$ & [m] & standard deviation of droplet radius \\
\hline$\kappa^{[c]}$ & [1] & chemical-composition parameter for spectrum $c$ \\
\hline$\kappa^{[0]}=1.28$ & {$[1]$} & $\mathrm{CCN}$-derived value of $\kappa$ for $\mathrm{NaCl}$ \\
\hline$\kappa^{[1]}=0.61$ & {$[1]$} & $\mathrm{CCN}$-derived value of $\kappa$ for $\left(\mathrm{NH}_{4}\right)_{2} \mathrm{SO}_{4}$ \\
\hline$\lambda_{D}$ & {$[\mathrm{~m}]$} & mean free path of water vapour in air \\
\hline$\lambda_{K}$ & {$[\mathrm{~m}]$} & length scale for heat transfer in air \\
\hline$a$ & [1] & water activity \\
\hline$b$ & {$[0,1, \ldots]$} & bin number enumerator \\
\hline CDNC & {$\left[\mathrm{m}^{-3}\right]$} & cloud droplet number concentration \\
\hline$c$ & {$[0,1, \ldots]$} & chemical composition enumerator \\
\hline$c_{1}=4218$ & {$\left[\mathrm{~J} \mathrm{~kg}^{-1} \mathrm{~K}^{-1}\right]$} & specific heat capacity of liquid water \\
\hline$c_{p}\left(q_{\mathrm{v}}\right)$ & {$\left[\mathrm{J} \mathrm{kg}^{-1} \mathrm{~K}^{-1}\right]$} & specific heat capacity of moist air \\
\hline$c_{p \mathrm{~d}}=1005$ & {$\left[\mathrm{~J} \mathrm{~kg}^{-1} \mathrm{~K}^{-1}\right]$} & specific heat capacity of dry air \\
\hline$c_{p \mathrm{v}}=1850$ & {$\left[\mathrm{~J} \mathrm{~kg}^{-1} \mathrm{~K}^{-1}\right]$} & specific heat capacity of water vapour \\
\hline$D\left(\lambda_{D}, r_{\mathrm{w}}\right)$ & {$\left[\mathrm{m}^{2} \mathrm{~s}^{-1}\right]$} & diffusivity of water vapour in air (transition régime) \\
\hline$D_{0}=2.21 \times 10^{5}$ & {$\left[\mathrm{~m}^{2} \mathrm{~s}^{-1}\right]$} & diffusivity of water vapour in air (continuum régime) \\
\hline$F(x, t)$ & $\mathrm{n} / \mathrm{a}$ & ODE system right-hand side \\
\hline$f\left(x_{i}\right)$ & $\mathrm{n} / \mathrm{a}$ & the function used in Newton-Raphson iteration \\
\hline$g=9.8067$ & {$\left[\mathrm{~m} \mathrm{~s}^{-2}\right]$} & gravitational acceleration \\
\hline$h$ & {$[1,2, \ldots]$} & BDF formula order \\
\hline$i$ & {$[0,1, \ldots]$} & solver time-step enumerator \\
\hline$j$ & {$[0,1, \ldots]$} & root-finding iteration enumerator \\
\hline$K\left(\lambda_{K}, r_{\mathrm{w}}\right)$ & {$\left[\mathrm{J} \mathrm{m}^{-1} \mathrm{~s}^{-1} \mathrm{~K}^{-1}\right]$} & thermal conductivity of air (transition régime) \\
\hline$K_{0}=2.4 \times 10^{-2}$ & {$\left[\mathrm{~J} \mathrm{~m}^{-1} \mathrm{~s}^{-1} \mathrm{~K}^{-1}\right]$} & thermal conductivity of air (continuum régime) \\
\hline$k$ & {$[0,1,2, \ldots]$} & spectrum moment enumerator \\
\hline LWC & {$\left[\mathrm{kg} \mathrm{m}^{-3}\right]$} & liquid water content \\
\hline$l_{\mathrm{v}}(T)$ & {$\left[\mathrm{J} \mathrm{kg}^{-1}\right]$} & latent heat of evaporation \\
\hline$l_{\mathrm{v} 0}=2.5 \times 10^{6}$ & {$\left[\mathrm{~J} \mathrm{~kg}^{-1}\right]$} & latent heat of evaporation at the triple point \\
\hline$M$ & {$[\mathrm{~kg}]$} & particle mass \\
\hline$m$ & {$[0,1, \ldots]$} & log-normal mode enumerator \\
\hline$N=\mathrm{CDNC} / \rho$ & {$\left[\mathrm{kg}^{-1}\right]$} & cloud droplet specific concentration \\
\hline$N^{[c]}$ & {$\left[\mathrm{kg}^{-1}\right]$} & total specific concentration in spectrum $c$ \\
\hline$N^{[c, b]}$ & {$\left[\mathrm{kg}^{-1}\right]$} & specific concentration in bin $b$ of spectrum $c$ \\
\hline$N_{b}, N_{b}^{[c]}$ & [1] & number of bins (in size spectrum $c$ ) \\
\hline$N_{c}$ & [1] & number of chemical components \\
\hline$N_{m}, N_{m}^{[c]}$ & {$\left[\mathrm{m}^{-3}\right]$} & total concentration in a log-normal mode \\
\hline$n_{\mathrm{d}}, n_{\mathrm{d}}^{[c]}$ & {$\left[\mathrm{kg}^{-1} \mathrm{~m}^{-1}\right]$} & dry aerosol specific concentration density \\
\hline$n_{\mathrm{w}}^{[c]}$ & {$\left[\mathrm{kg}^{-1} \mathrm{~m}^{-1}\right]$} & wet aerosol specific concentration density \\
\hline$p$ & {$[\mathrm{~Pa}]$} & air-parcel pressure \\
\hline$p_{0}=611.73$ & {$[\mathrm{~Pa}]$} & water vapour pressure at the triple point \\
\hline$p_{\mathrm{V}}$ & {$[\mathrm{Pa}]$} & partial pressure of water vapour \\
\hline
\end{tabular}




\begin{tabular}{|c|c|c|}
\hline$p_{\mathrm{v} \infty}(T)$ & {$[\mathrm{Pa}]$} & equilibrium vapour pressure (plane surface, pure water) \\
\hline$p_{\mathrm{vs}}(T, \ldots)$ & {$[\mathrm{Pa}]$} & equilibrium vapour pressure (solution droplet) \\
\hline$Q$ & {$[\mathrm{~J}]$} & particle heat content \\
\hline$q_{\mathrm{v}}$ & [1] & air-parcel specific humidity \\
\hline$R\left(q_{\mathrm{v}}\right)$ & {$\left[\mathrm{J} \mathrm{K}^{-1} \mathrm{~kg}^{-1}\right]$} & gas constant of moist air \\
\hline$R_{\mathrm{d}}=287.1$ & {$\left[\mathrm{~J} \mathrm{~K}^{-1} \mathrm{~kg}^{-1}\right]$} & gas constant of dry air \\
\hline$R_{\mathrm{V}}=461.4$ & {$\left[\mathrm{~J} \mathrm{~K}^{-1} \mathrm{~kg}^{-1}\right]$} & gas constant of water vapour \\
\hline $\mathrm{RH}=p_{\mathrm{v}} / p_{\mathrm{v} \infty}$ & {$[1]$} & air-parcel relative humidity \\
\hline$r_{0}, r_{1}, r_{a}, r_{b}$ & {$[\mathrm{~m}]$} & helper symbols in Eqs (18) and (25) \\
\hline$r_{\text {eff }}$ & [m] & cloud droplet effective radius \\
\hline$r_{\mathrm{d}}, r_{\mathrm{dl}}^{[c, b]}, r_{\mathrm{dr}}^{[c, b]}$ & {$[\mathrm{m}]$} & particle dry radius (at left/right bin boundary) \\
\hline & {$[\mathrm{m}]$} & mode radius of a log-normal mode \\
\hline$r_{\min }, r_{\max }$ & {$[\mathrm{m}]$} & cloud droplet spectrum range ( 1 and $25 \mu \mathrm{m})$ \\
\hline$r_{\mathrm{w}}, r_{\mathrm{wl}}^{[c, b]}, r_{\mathrm{wr}}^{[c, b]}$ & {$[\mathrm{m}]$} & particle wet radius (at left/right bin boundary) \\
\hline$S, S_{\max }$ & {$[1]$} & supersaturation (maximum) \\
\hline$t, t_{i}$ & {$[\mathrm{~s}]$} & time (at model time-step $i$ ) \\
\hline$T$ & {$[\mathrm{~K}]$} & air-parcel temperature \\
\hline$T^{\prime}$ & {$[\mathrm{K}]$} & temperature \\
\hline$T_{0}=273.16$ & {$[\mathrm{~K}]$} & temperature of the triple point of water \\
\hline$T_{\mathrm{w}}, T_{\mathrm{wl}}^{[c, b]}, T_{\mathrm{wr}}^{[c, b]}$ & {$[\mathrm{K}]$} & particle temperature (at left/right bin boundary) \\
\hline$w$ & {$\left[\mathrm{~m} \mathrm{~s}^{-1}\right]$} & air-parcel vertical velocity \\
\hline$x$ & $\mathrm{n} / \mathrm{a}$ & vector of dependent variables in ODE system \\
\hline$Z_{k}$ & {$\left[\mathrm{~m}^{k} \mathrm{~kg}^{-1}\right]$} & helper symbol in Eqs. (24) and (25) \\
\hline
\end{tabular}

\section{Supplementary material related to this article is available online at: http://www.geosci-model-dev.net/4/15/2011/ gmd-4-15-2011-supplement.zip.}

Acknowledgements. This work was supported by the European Union 6 FP IP EUCAARI (European Integrated project on Aerosol Cloud Climate and Air Quality interactions) No. 036833-2 and the Polish MNiSW grant 396/6/PR UE/2007/7. We thank JeanLouis Brenguier (Météo-France) for providing an inspiration for this study. Comments on the manuscript by Wojciech W. Grabowski (NCAR) are acknowledged. We thank Jeff Snider and Hannele Korhonen for their insightful reviews. We also appreciate the work of the developers of the free/libre/opensource software which served as a base for the implementation of the model: Boost.Units (http://www.boost.org), SUNDIALS (http://computation.llnl.gov/casc/sundials/), GSL (http://www.gnu. org/software/gsl/) and gnuplot (http://www.gnuplot.info/).

Edited by: O. Boucher

\section{References}

Aitken, J.: On dust, fogs, and clouds, T. Roy. Soc. Edinburgh (1880-1881), 30, 34-64, (reprinted in: The Collected Scientific Papers of John Aitken, LLD, FRS, edited by: Knott, C. G., Cambridge Univ. Press, 1923), 1880.

Anttila, T., Kerminen, V.-M., Kulmala, M., Laaksonen, A., and O'Dowd, C. D.: Modelling the formation of organic particles in the atmosphere, Atmos. Chem. Phys., 4, 1071-1083, doi:10.5194/acp-4-1071-2004, 2004.

Bower, K., Choularton, T., Latham, J., Sahraei, J., and Salter, S.: Computational assessment of a proposed technique for global warming mitigation via albedo-enhancement of marine stratocumulus clouds, Atmos. Res., 82, 328-336, doi:10.1016/j.atmosres.2005.11.013, 2006.

Brenguier, J.-L., Pawlowska, H., Schüller, L., Preusker, R., Fischer, J., and Fouquart, Y.: Radiative properties of boundary layer clouds: droplet effective radius versus number concentration, J. Atmos. Sci., 57, 803-821, doi:10.1175/15200469(2000)057<0803:RPOBLC > 2.0.CO;2, 2000.

Cohen, S. and Hindmarsh, A.: CVODE, A stiff/nonstiff ODE solver in C, Comput. Phys., 10, 138-143, (also available as LLNL technical report UCRL-JC-121014), 1996.

Debry, E., Fahey, K., Sartelet, K., Sportisse, B., and Tombette, M.: Technical Note: A new SIze REsolved Aerosol Model (SIREAM), Atmos. Chem. Phys., 7, 1537-1547, doi:10.5194/acp-7-1537-2007, 2007.

Feingold, G. and Heymsfield, A.: Parameterizations of condensational growth of droplets for use in general circulation models, J. Atmos. Sci., 49, 2325-2342, doi:10.1175/15200469(1992)049<2325:POCGOD>2.0.CO;2, 1992.

Fitzgerald, J.: Effect of aerosol composition on cloud droplet size distribution: a numerical study, J. Atmos. Sci., 31, doi:10.1175/1520-0469(1974)031<1358:EOACOC > 2.0.CO;2, 1974.

Fuchs, N. and Sutugin, A.: Highly Dispersed Aerosols, Ann Arbor Science Publ., Ann Arbor, Michigan, 1970. 
Galassi, M., Davies, J., Theiler, J., Gough, B., Jungman, G., Alken, P., Booth, M., and Rossi, F.: GNU Scientific Library Reference Manual, 3rd edn., Network Theory Ltd., Bristol, 2009.

Gelbard, F.: Modelling multicomponent aerosol particle growth by vapor condensation, Aerosol Sci. Tech., 12, 399-411, doi:10.1080/02786829008959355, 1990.

Ghan, S., Guzman, G., and Abdul-Razzak, H.: Competition between sea salt and sulfate particles as cloud condensation nuclei, J. Atmos. Sci., 55, 3340-3347, doi:10.1175/15200469(1998)055<3340:CBSSAS > 2.0.CO;2, 1998.

Grabowski, W. W. and Wang, L.-P.: Diffusional and accretional growth of water drops in a rising adiabatic parcel: effects of the turbulent collision kernel, Atmos. Chem. Phys., 9, 2335-2353, doi:10.5194/acp-9-2335-2009, 2009.

Grabowski, W. W., Andrejczuk, M., and Wang, L.P.: Droplet growth in a bin warm-rain scheme with Twomey CCN activation, Atmos. Res., 99(2), 290-301, doi:10.1016/j.atmosres.2010.10.020, 2010.

Hänel, G.: The role of aerosol properties during the condensational stage of cloud: a reinvestigation of numerics and microphysics, Beitr. Phys. Atmos., 60, 321-339, 1987.

Hindmarsh, A., Brown, P., Grant, K., Lee, S., Serban, R., Shumaker, D., and Woodward, C.: SUNDIALS: suite of nonlinear and differential/algebraic equation solvers, ACM T. Math. Software, 31, 363-396, doi:10.1145/1089014.1089020, (also available as LLNL technical report UCRL-JP-200037), 2005.

Howell, W.: The growth of cloud drops in uniformly cooled air, J. Meteorol., 6, 134-149, doi:10.1175/15200469(1949)006<0134:TGOCDI>2.0.CO;2, 1949.

Jacobson, M.: Fundamentals of Atmospheric Modeling, Cambridge Univ. Press, Cambridge, 1st edn., (2nd edn.: 2005), 1999.

Johnson, D.: Analytical solutions for cloud-drop concentration, J. Atmos. Sci., 38, 215-218, doi:10.1175/15200469(1981)038<0215:ASFCDC>2.0.CO;2, 1981.

Khvorostyanov, V. and Curry, J.: Parameterization of cloud drop activation based on analytical asymptotic solutions to the supersaturation equation, J. Atmos. Sci., 65, 1905-1925, doi:10.1175/2009JAS2811.1, 2009.

Köhler, H.: The nucleus in and the growth of hygroscopic droplets, T. Faraday Soc., 32, 1152-1161, doi:10.1039/TF9363201152, 1936.

Korhonen, H., Kerminen, V.-M., Lehtinen, K. E. J., and Kulmala, M.: CCN activation and cloud processing in sectional aerosol models with low size resolution, Atmos. Chem. Phys., 5, 2561-2570, doi:10.5194/acp-5-2561-2005, 2005.

Kornfeld, P.: Numerical solution for condensation of atmospheric vapor on soluble and insoluble nuclei, J. Atmos. Sci., 27, 256-264, doi:10.1175/15200469(1970)027<0256:NSFCOA > 2.0.CO;2, 1970.

Kraus, E. and Smith, B.: Theoretical aspects of cloud drop distributions, Aust. J. Sci. Res., 2, 376-388, doi:10.1071/CH9490376, 1949.

Kreidenweis, S., Walcek, C., Feingold, G., Gong, W., Jacobson, M., Kim, C.-H., Liu, X., Penner, J., Nenes, A., and Seinfeld, J.: Modification of aerosol mass and size distribution due to aqueous phase $\mathrm{SO}_{2}$ oxidation in clouds: comparisons of several models, J. Geophys. Res., 108, 4213, doi:10.1029/2002JD002697, 2003.
Kulmala, M., Asmi, A., Lappalainen, H. K., Carslaw, K. S., Pöschl, U., Baltensperger, U., Hov, Ø., Brenquier, J.-L., Pandis, S. N., Facchini, M. C., Hansson, H.-C., Wiedensohler, A., and O'Dowd, C. D.: Introduction: European Integrated Project on Aerosol Cloud Climate and Air Quality interactions (EUCAARI) - integrating aerosol research from nano to global scales, Atmos. Chem. Phys., 9, 2825-2841, doi:10.5194/acp-9-28252009, 2009a.

Kulmala, M., Asmi, A., Lappalainen, H. K., Carslaw, K. S., Pöschl, U., Baltensperger, U., Hov, Ø., Brenguier, J.-L., Pandis, S. N., Facchini, M. C., Hansson, H.-C., Wiedensohler, A., and O'Dowd, C. D.: Corrigendum to "Introduction: European Integrated Project on Aerosol Cloud Climate and Air Quality interactions (EUCAARI) - integrating aerosol research from nano to global scales" published in Atmos. Chem. Phys., 9, 2825-2841, 2009, Atmos. Chem. Phys., 9, 3443-3444, doi:10.5194/acp-9-3443-2009, 2009 b.

Laaksonen, A., Vesala, T., Kulmala, M., Winkler, P. M., and Wagner, P. E.: Commentary on cloud modelling and the mass accommodation coefficient of water, Atmos. Chem. Phys., 5, 461-464, doi:10.5194/acp-5-461-2005, 2005.

Langmuir, I.: Super-cooled water droplets in rising currents of cold saturated air, Tech. Rep. RL-223, General Electric Company, (reprinted in The Collected Works of Irving Langmuir, edited by: Suits, C. G. and Way, H. E., Pergamon Press, Oxford, 1961), 1944.

Lawson, R. P. and Blyth, A.: A comparison of optical measurements of liquid water content and drop size distribution in adiabatic regions of Florida cumuli, Atmos. Res., 47-48, 671-690, doi:10.1016/S0169-8095(98)00063-5, 1998.

Lee, I.-Y. and Pruppacher, H.: A comparative study on the growth of cloud drops by condensation using an air parcel model with and without entrainment, Pure Appl. Geophys., 115, 523-545, doi:10.1007/BF00876119, 1977.

Mason, B.: The Physics of Clouds, 1st edn., Oxford Univ. Press, London, (2nd edn.: Clarendon Press, Oxford, 1971), 1957.

Maxwell, J.: Diffusion, in: Encyclopædia Britannica, (reprinted in The Scientific Papers of James Clerk Maxwell, edited by: Niven, W. D., Dover Publications, New York, 1965), 625-646, 1878.

McFiggans, G., Artaxo, P., Baltensperger, U., Coe, H., Facchini, M. C., Feingold, G., Fuzzi, S., Gysel, M., Laaksonen, A., Lohmann, U., Mentel, T. F., Murphy, D. M., O’Dowd, C. D., Snider, J. R., and Weingartner, E.: The effect of physical and chemical aerosol properties on warm cloud droplet activation, Atmos. Chem. Phys., 6, 2593-2649, doi:10.5194/acp-6-25932006, 2006.

Mordy, W.: Computations of the growth by condensation of a population of cloud droplets, Tellus, 11, 16-44, doi:10.1111/j.21533490.1959.tb00003.x, 1959.

Neiburger, M. and Chien, C.: Computations of the growth of cloud drops by condensation using an electronic digital computer, in: Physics of Precipitation, edited by: Weickmann, H., 191-210, AGU, Washington, 1960.

Nenes, A., Chuang, P., Flagan, R., and Seinfeld, J.: A theoretical analysis of cloud condensation nucleus (CCN) instruments, J. Geophys. Res., 106, 3449-3474, doi:10.1029/ 2000JD900614, 2001a. 
Nenes, A., Ghan, S., Abdul-Razzak, H., Chuang, P., and Seinfeld, J.: Kinetic limitations on cloud droplet formation and impact on cloud albedo, Tellus B, 53, 133-149, doi:10.1034/j.1600-0889.2001.d01-12.x, 2001b.

O'Dowd, C., Smith, M., Consterdine, I., and Lowe, J.: Marine aerosol, sea-salt, and the marine sulphur cycle: a short review, Atmos. Environ., 31, 73-80, doi:10.1016/S13522310(96)00106-9, 1997.

Petters, M. D. and Kreidenweis, S. M.: A single parameter representation of hygroscopic growth and cloud condensation nucleus activity, Atmos. Chem. Phys., 7, 1961-1971, doi:10.5194/acp-71961-2007, 2007.

Rogers, R. and Yau, M.: A Short Course in Cloud Physics, Butterworth-Heinemann, Woburn, Massachusetts, 1989.

Romakkaniemi, S., Kokkola, H., Lehtinen, K. E. J., and Laaksonen, A.: The influence of nitric acid on the cloud processing of aerosol particles, Atmos. Chem. Phys., 6, 16271634, doi:10.5194/acp-6-1627-2006, 2006.

Schabel, M. and Watanabe, S.: Boost.Units: zero-overhead dimensional analysis and unit/quantity manipulation and conversion, in: Boost Library Documentation, available at: http://www. boost.org/doc/libs/ (last access: July 2010), 2008.

Snider, J., Guibert, S., Brenguier, J.-L., and Putaud, J.-P.: Aerosol activation in marine stratocumulus clouds: 2. Köhler and parcel theory closure studies, J. Geophys. Res., 108, 8629, doi:10.1029/2002JD002692, 2003.

Squires, P.: The growth of cloud drops by condensation. I. General characteristics, Aust. J. Sci. Res., A5, 59-86,
doi:10.1071/CH9520059, 1952.

Stevens, B. and Feingold, G.: Untangling aerosol effects on clouds and precipitation in a buffered system, Nature, 461, 607-613, doi:10.1038/nature08281, 2009.

Takeda, T. and Kuba, N.: Numerical study of the effect of CCN on the size distribution of cloud droplets. Part I. Cloud droplets in the stage of condensationa growth, J. Meteorol. Soc. Jpn., 60, 978-993, 1982.

Tsuji, M.: On the growth of cloud particles and the degree of supersaturation in convective clouds, J. Meteorol. Soc. Jpn., 28, 122-130, 1950.

Twomey, S.: The nuclei of natural cloud formation. Part II: The supersaturation in natural clouds and the variation of cloud droplet concentration, Pure Appl. Geophys., 43, 243-249, doi:10.1007/BF01993560, 1959.

Vesala, T., Kulmala, M., Rudolf, R., Vrtala, A., and Wagner, P.: Models for condensational growth and evaporation of binary aerosol particles, J. Aerosol Sci., 28, 565-598, doi:10.1016/S0021-8502(96)00461-2, 1997.

Whitby, K.: The physical characteristics of sulfur aerosols, Atmos. Environ., 12, 135-159, doi:10.1016/0004-6981(78)90196-8, (reprinted in: Haagen-Smit Prize Special Supplement, Atmos. Environ., 41, S25-S49, doi:10.1016/j.atmosenv.2007.10.057, 2007), 1978.

Williams, M. and Loyalka, S.: Aerosol Science: Theory and Practice, Pergamon Press, New York, 1991.

Wouwer, A., Saucez, P., and Schiesser, W. (Eds.): Adaptive Method of Lines, Chapman and Hall/CRC, Boca Raton, Florida, 2001. 